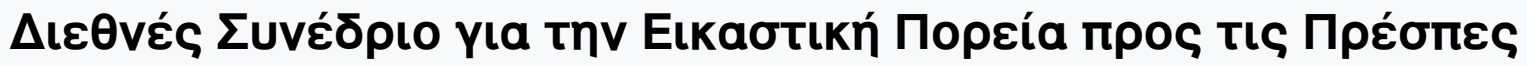

Tóp. 3 (2011)

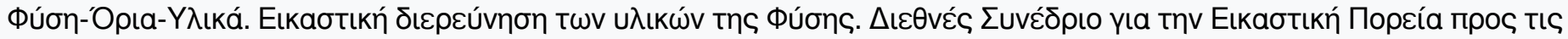
Пре́бாєৎ

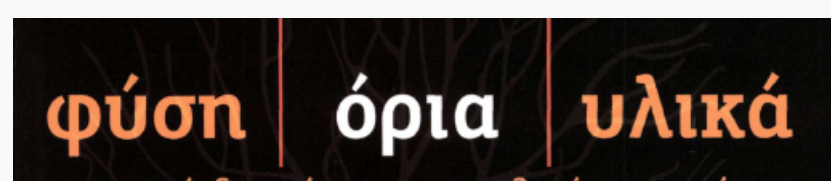

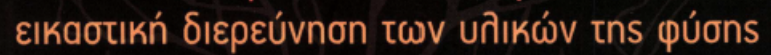

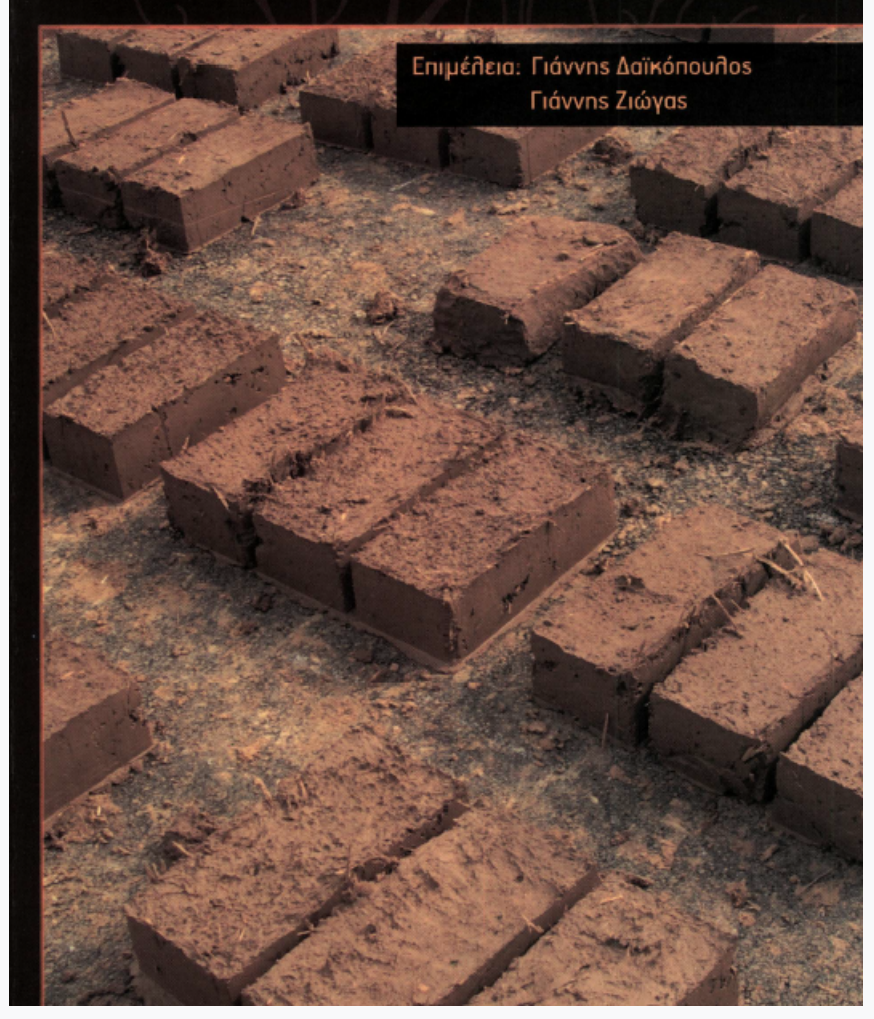

\section{Фúon -Opıa-Y入ıкá}

$\Sigma \tau \varepsilon ́ \lambda \lambda a \Gamma ı a ́ v v \eta \varsigma$ Zı́́yas

doi: $10.12681 /$ visualmarch.3086 


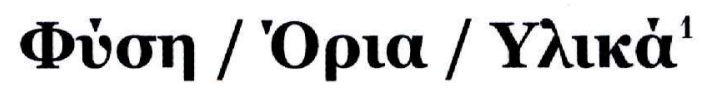

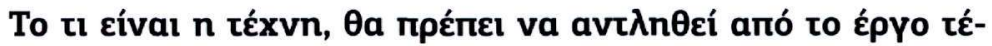

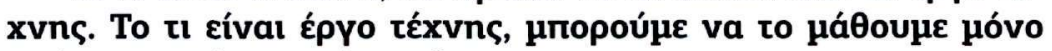 \\ anó tnv oưía tnৎ̧ téxvns².
}

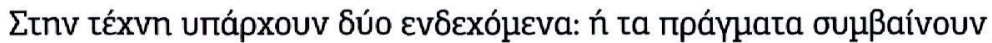

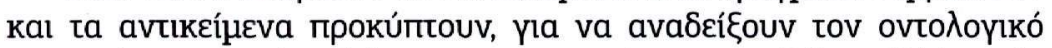

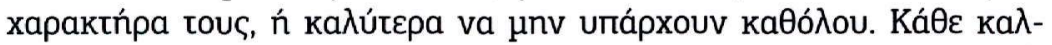

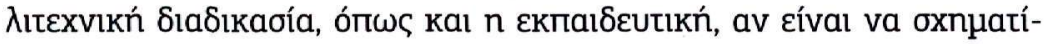

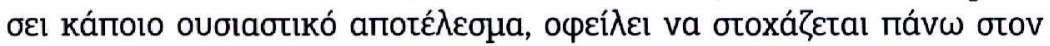

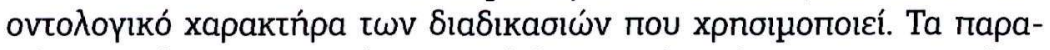

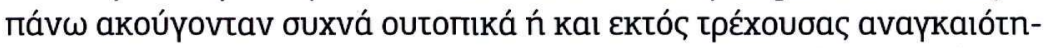

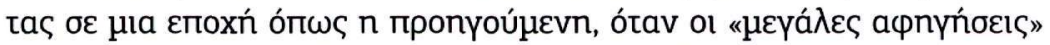

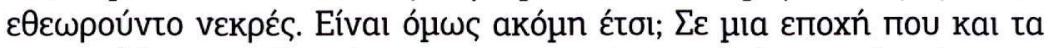

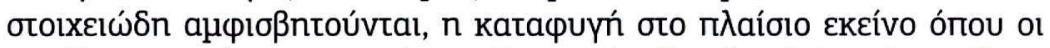

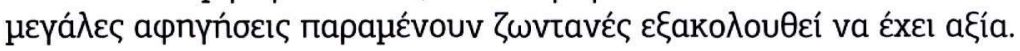

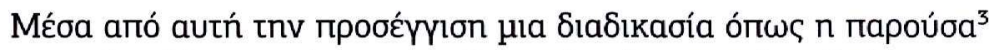

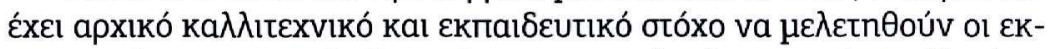

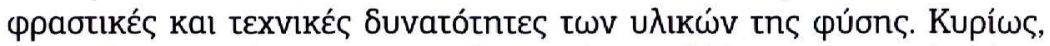

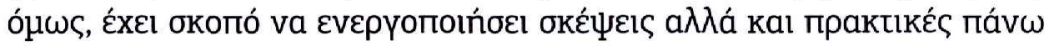

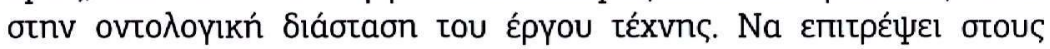

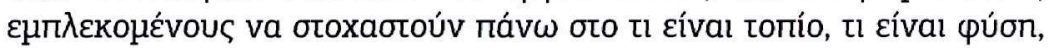

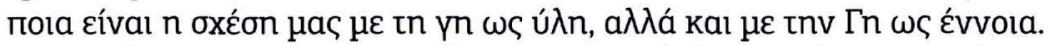

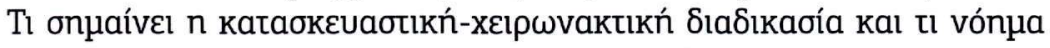

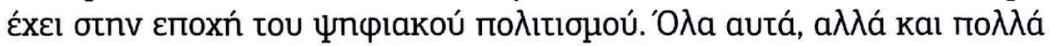

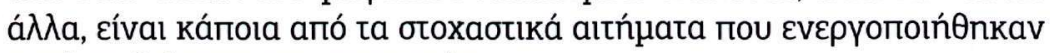

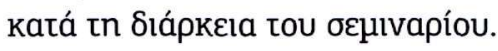

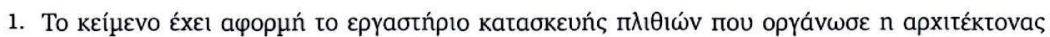

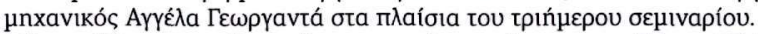

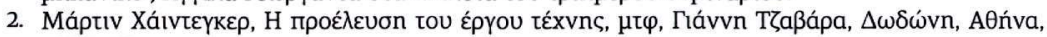
$1986,30$.

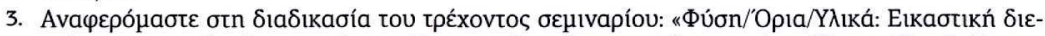

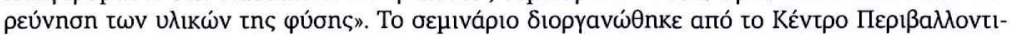

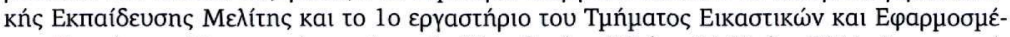

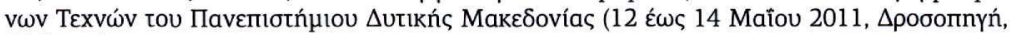
$\Phi \lambda \omega ́ \rho ı v a)$. 


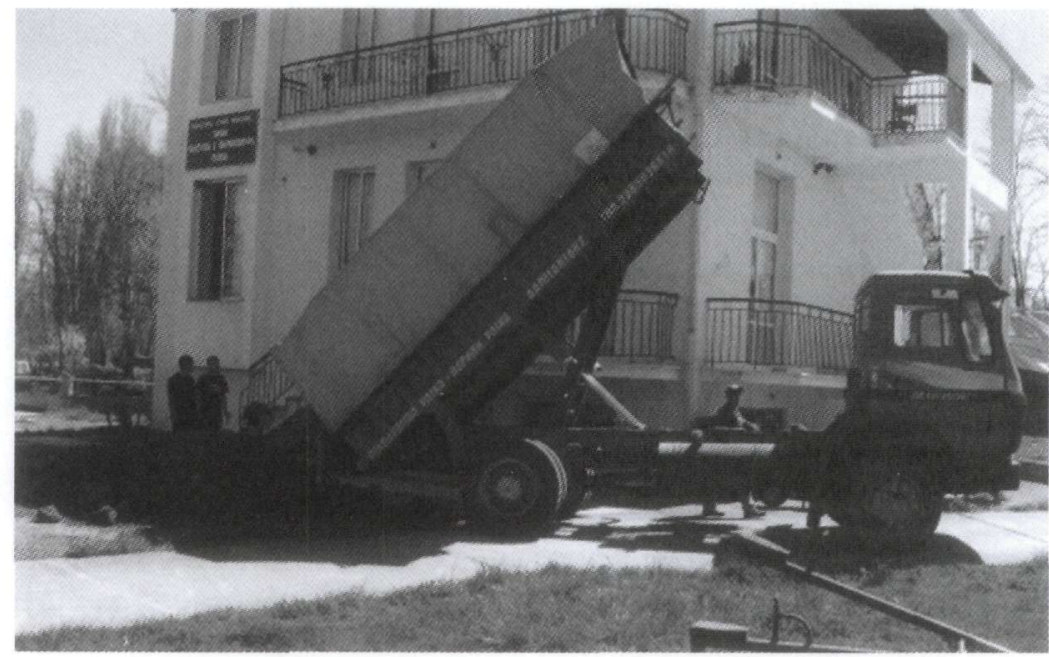

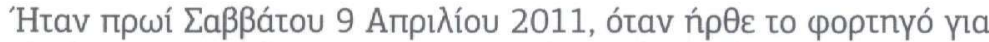

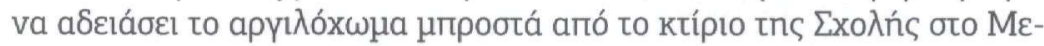

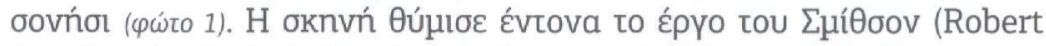

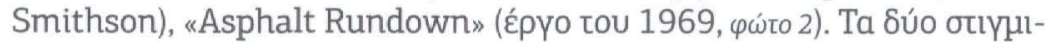

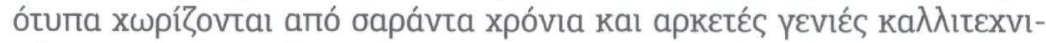

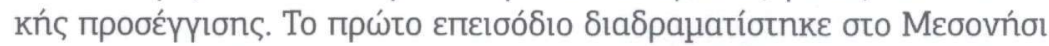

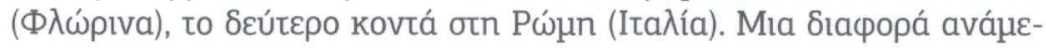

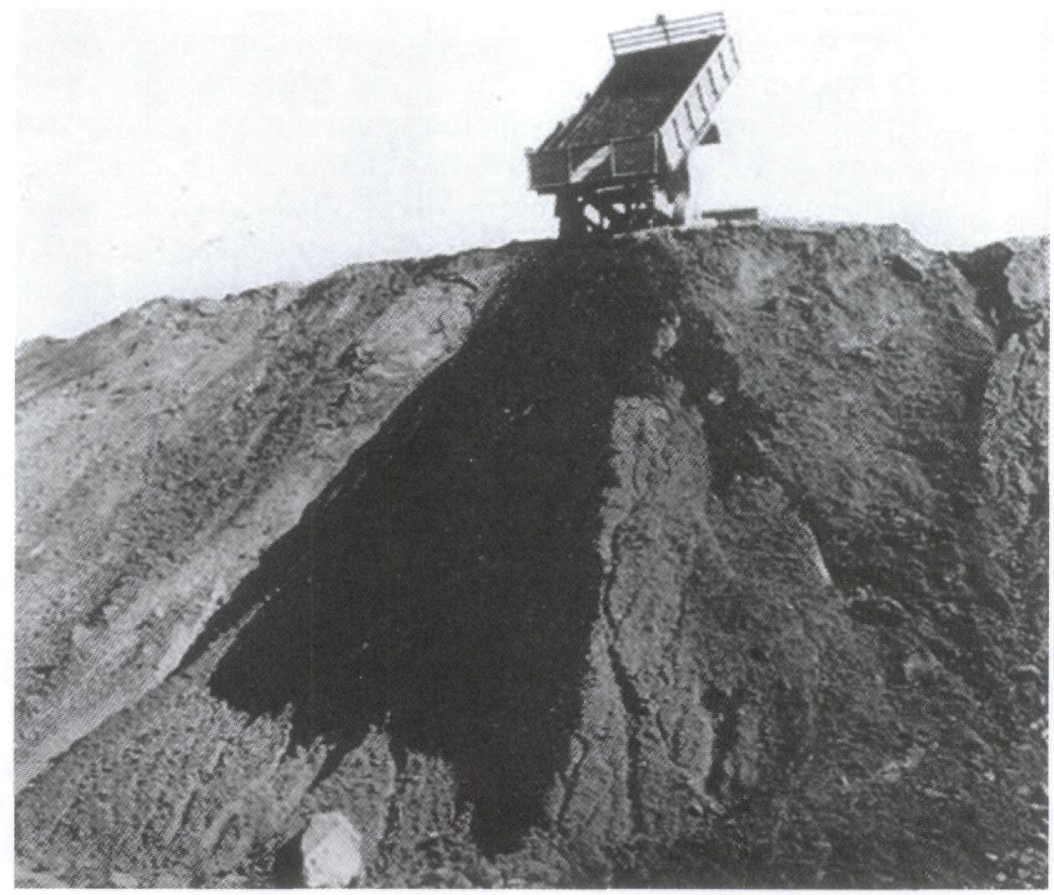

1.

9 Aлриіiou 2011: то

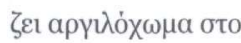

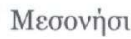

2.

Robert

Smithson,

Asphalt

Rundown,

$P \omega ́ \mu \eta$ 


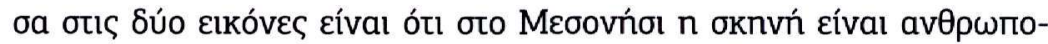

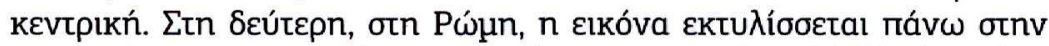

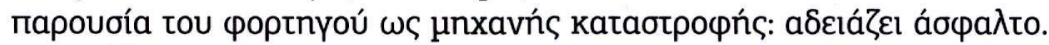

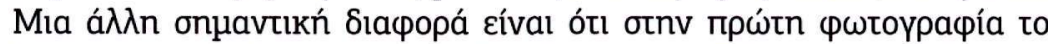

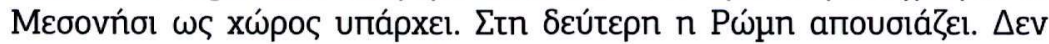

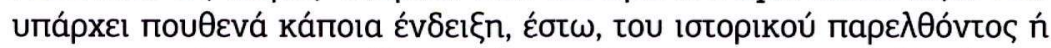

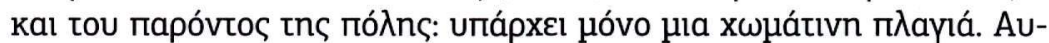

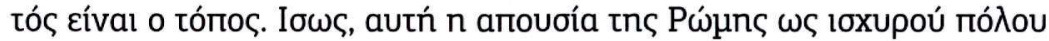

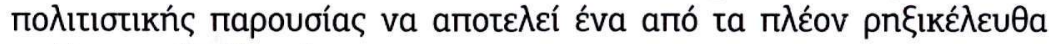

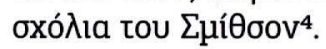

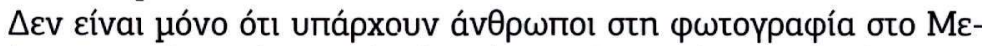

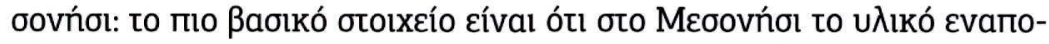

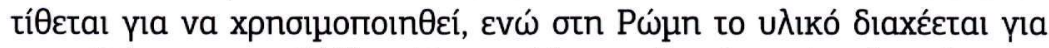

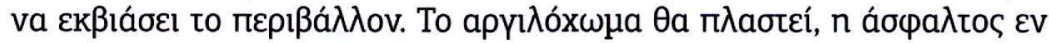

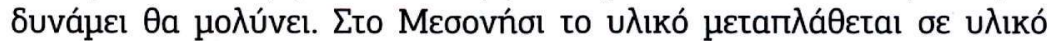

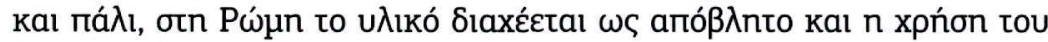

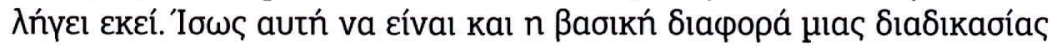

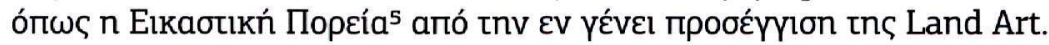

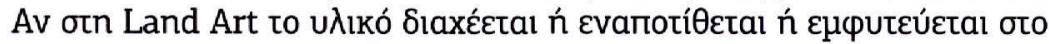

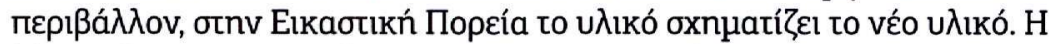

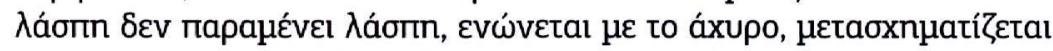

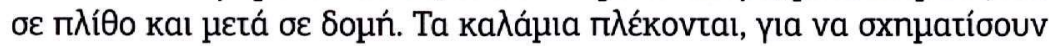

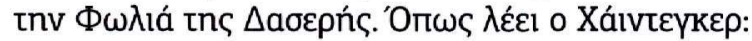

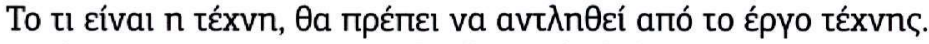

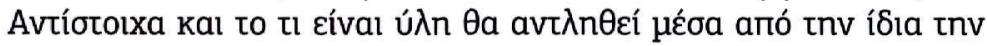

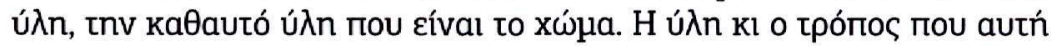

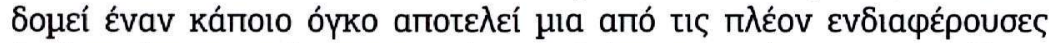

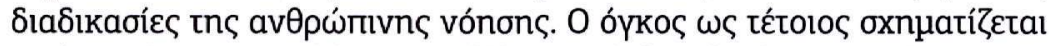

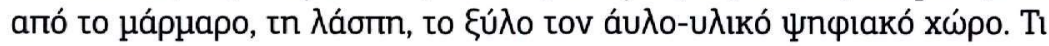

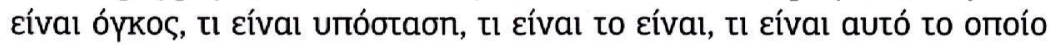

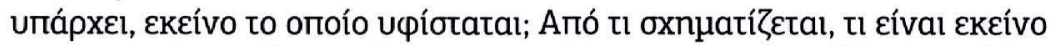

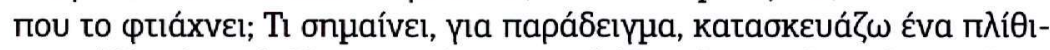

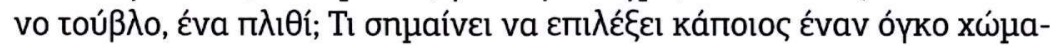

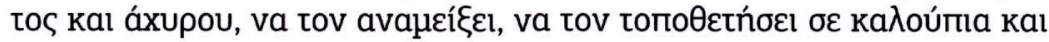

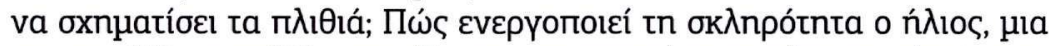

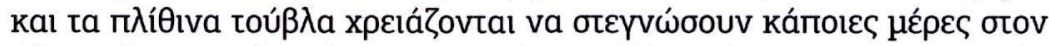

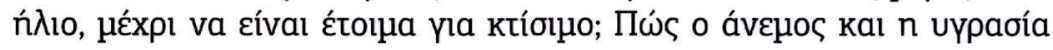

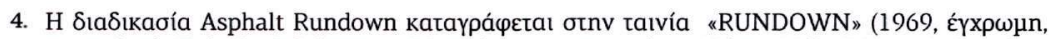

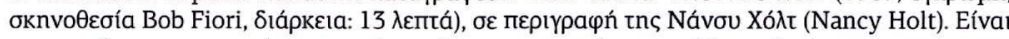

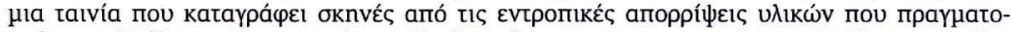

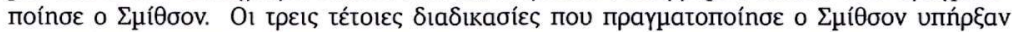

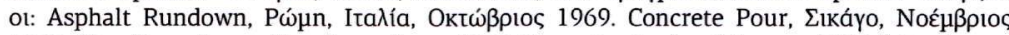

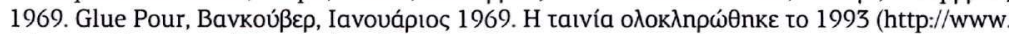
robertsmithson.com/films/txt/rundown.html).

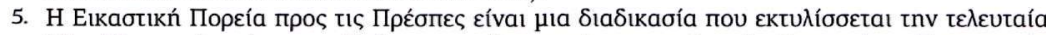

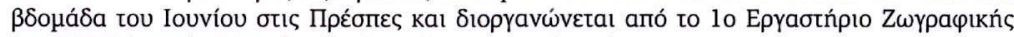

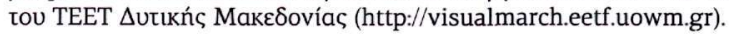




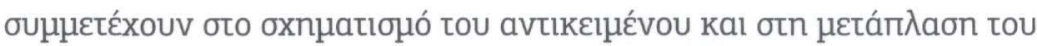

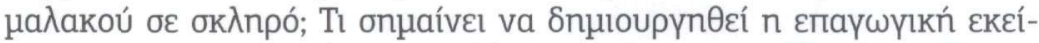

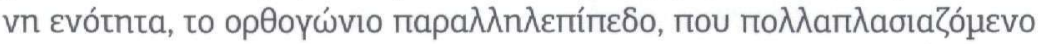

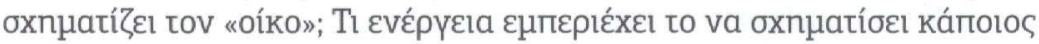

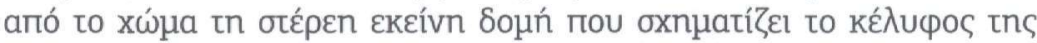

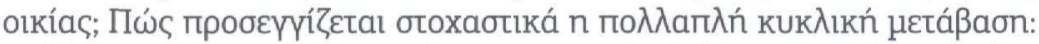

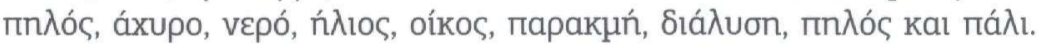

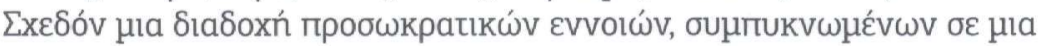

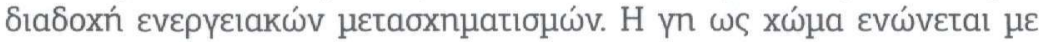

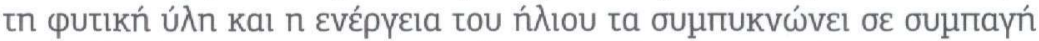

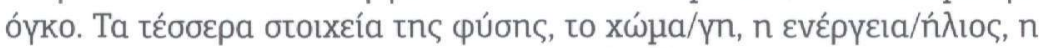

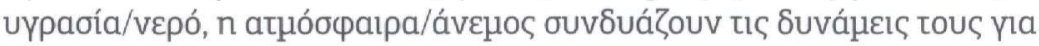

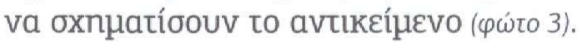

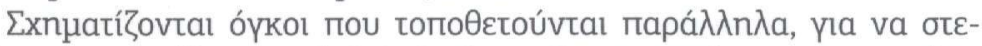

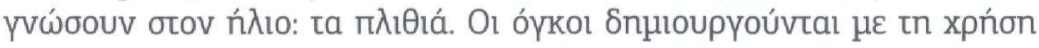

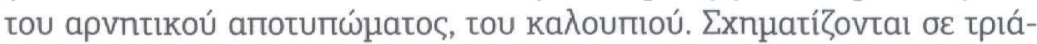

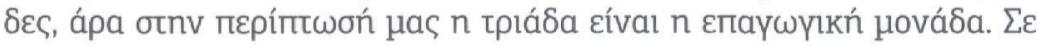
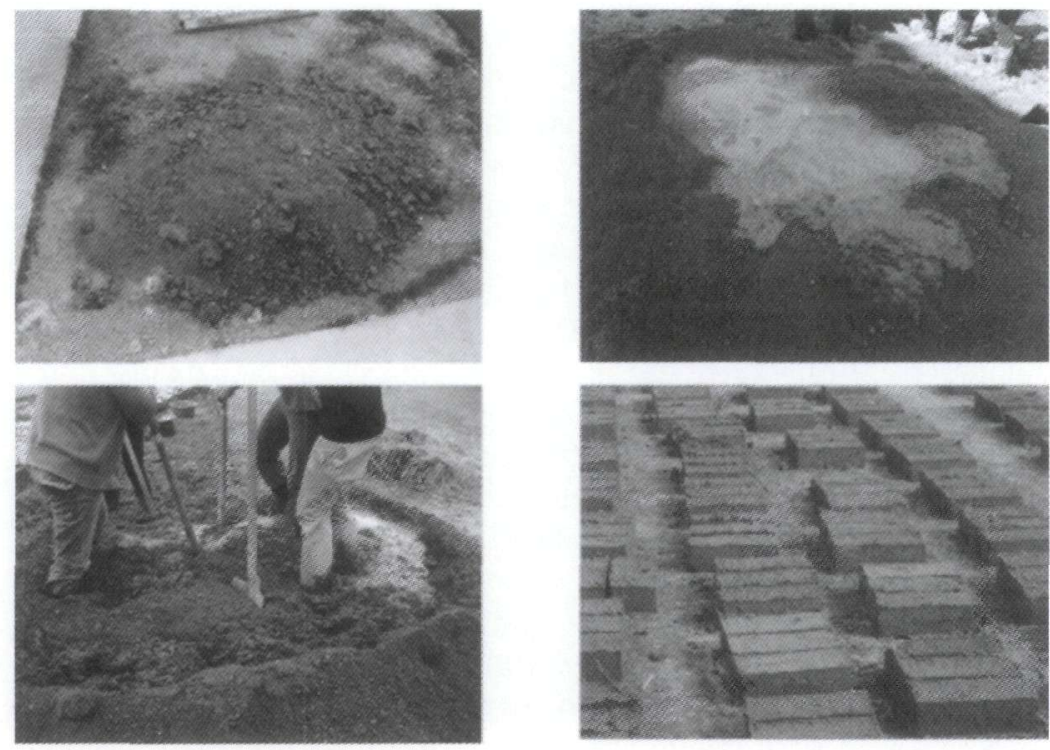

3 .

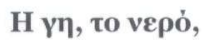
o ท่̀

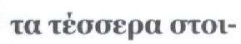

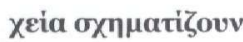
tov òjko

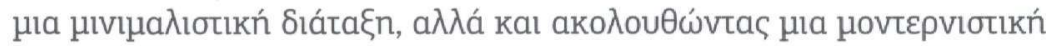

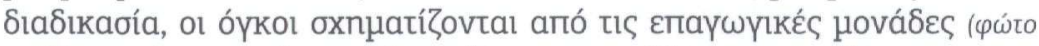

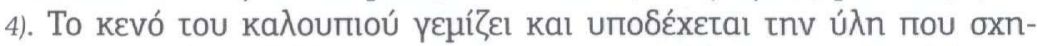

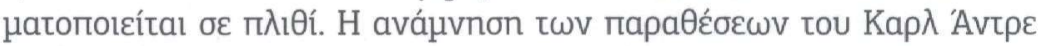

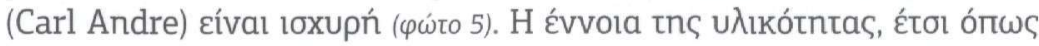

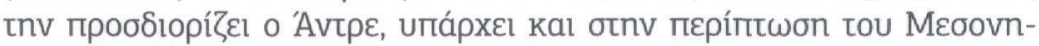

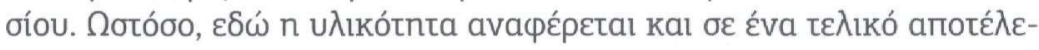

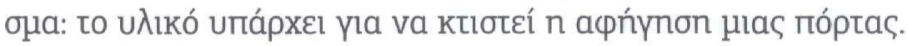


4.

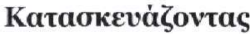

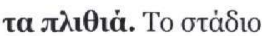

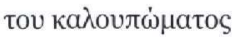

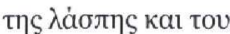

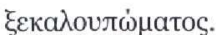

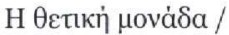

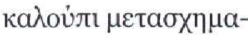

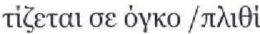
5.

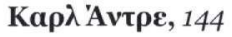
Graphite Silence, кúßо үрафітп, 10×340×340 عк., 2005
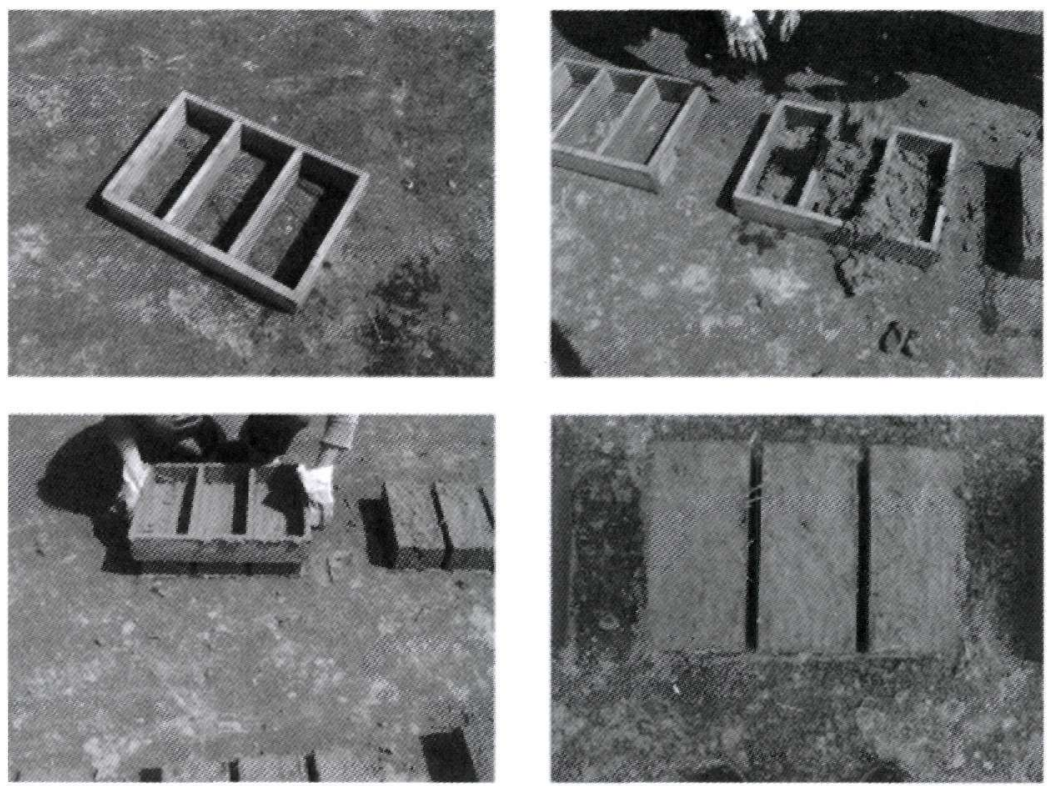

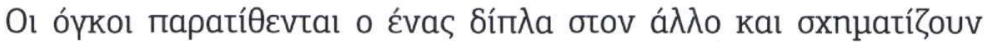

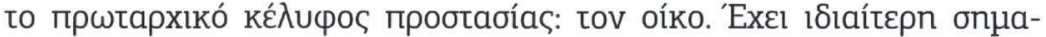

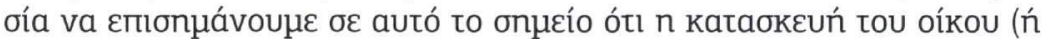

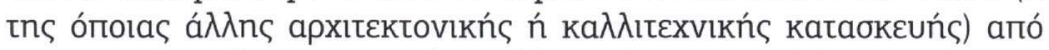

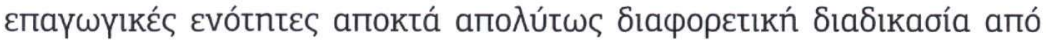

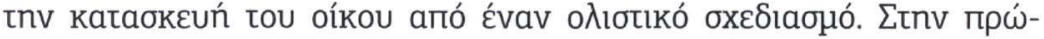

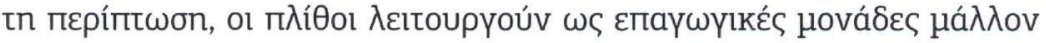

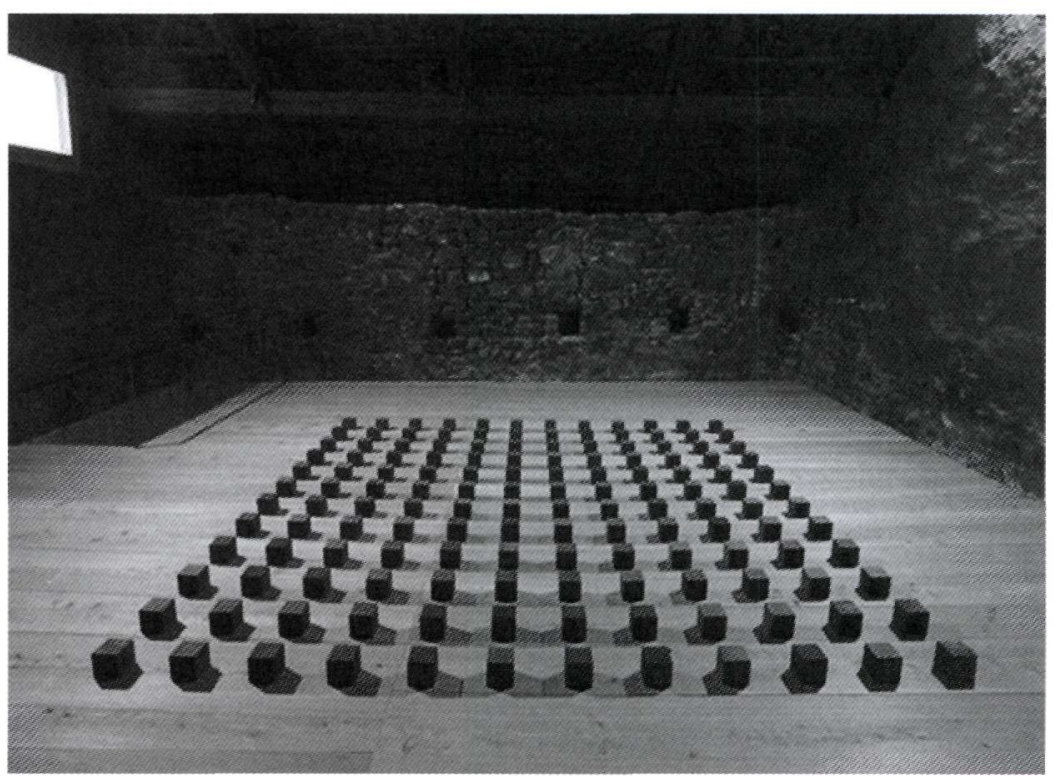




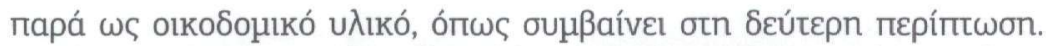

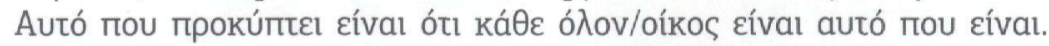

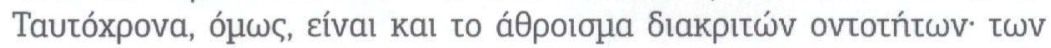

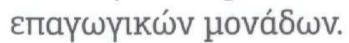

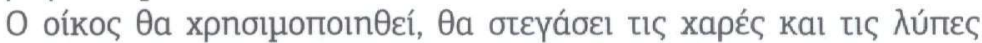

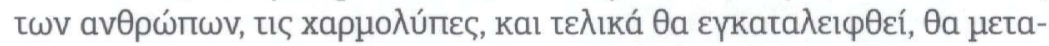

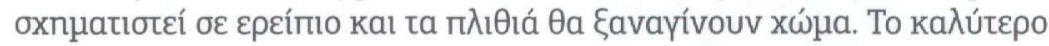

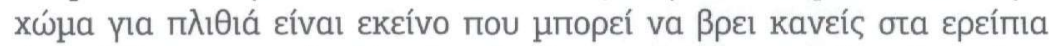

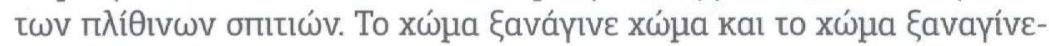

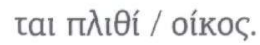

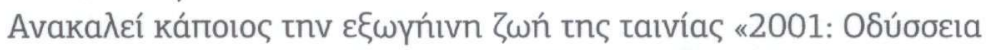

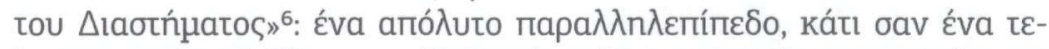

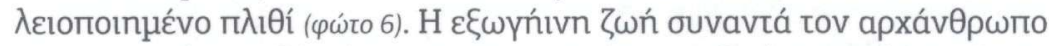

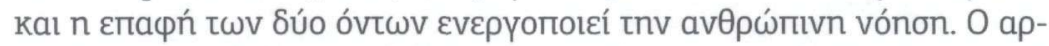

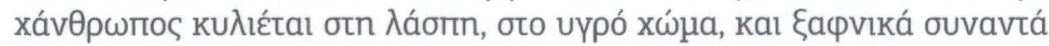

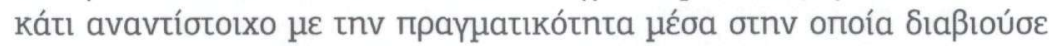

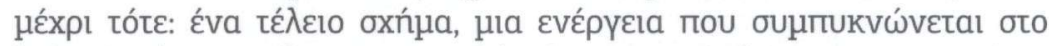

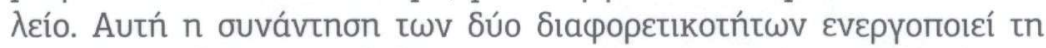

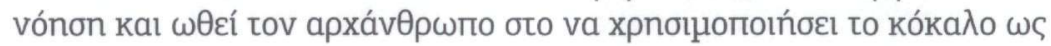

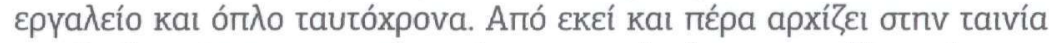

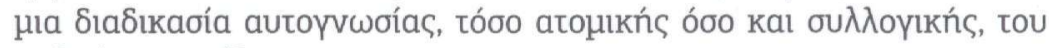

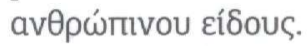

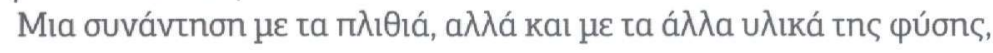

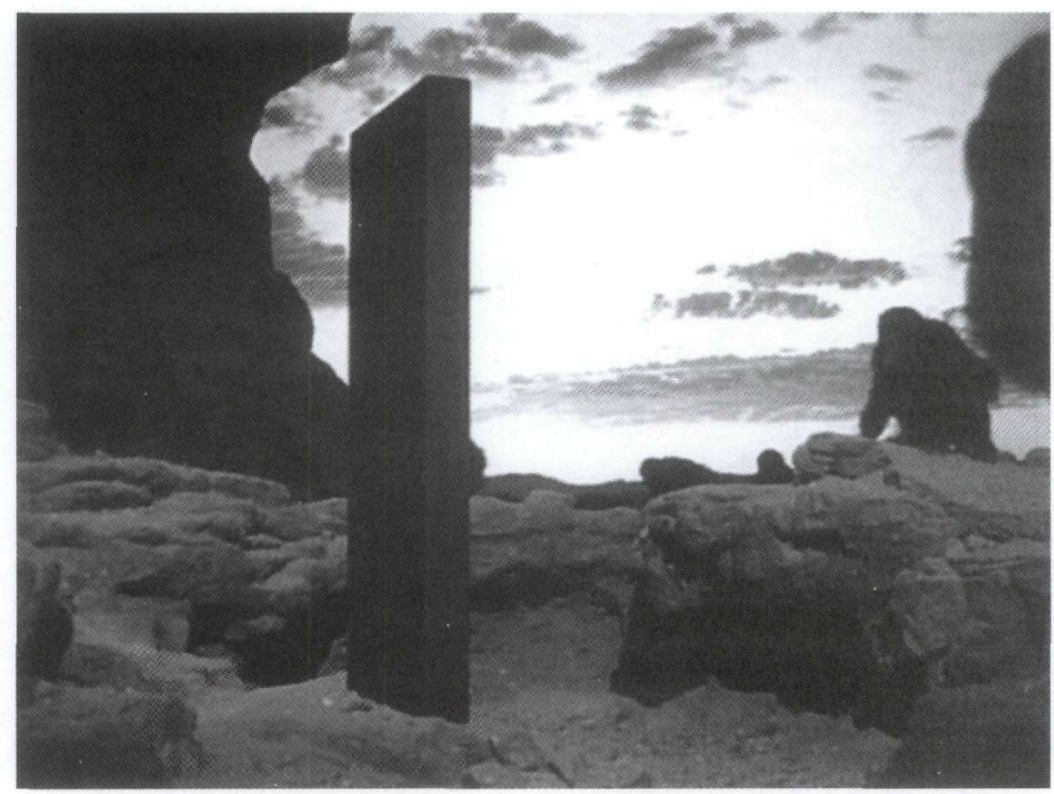

6.

Stanley Kubrick,

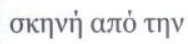
Taivia 2001:

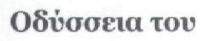
$\Delta$ ıatrìnatos

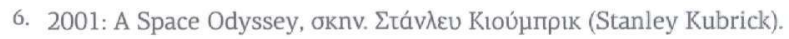




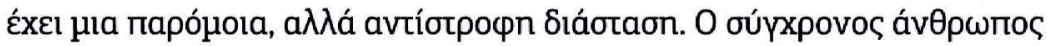

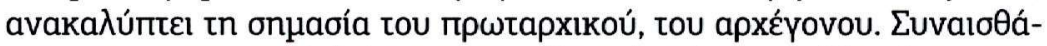

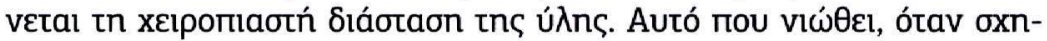

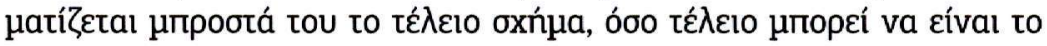

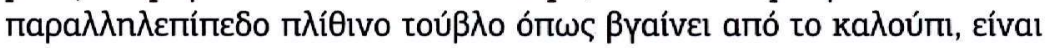

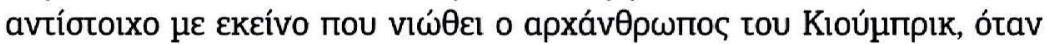

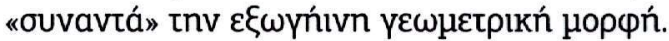

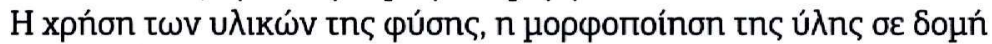

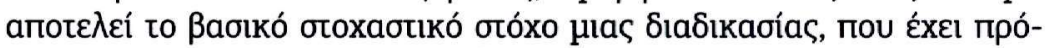

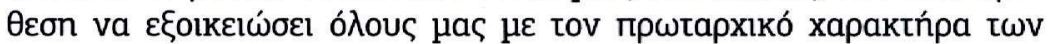

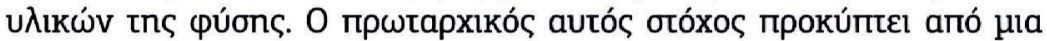

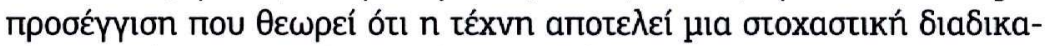

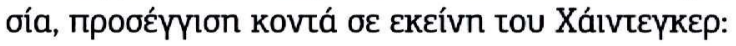

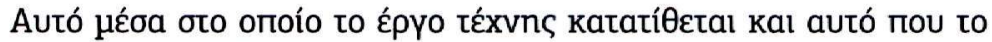

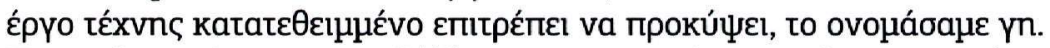

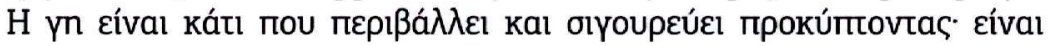

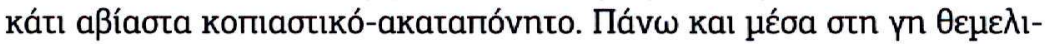

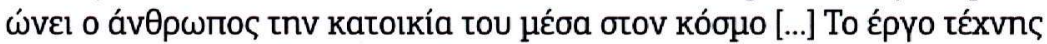

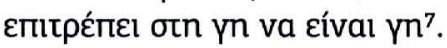

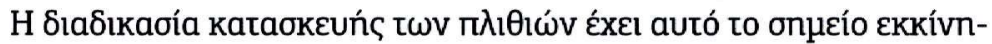

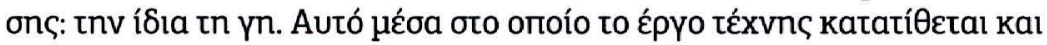

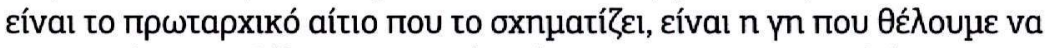

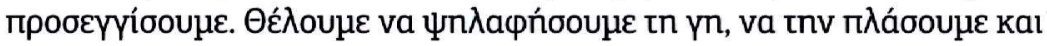

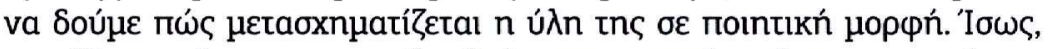

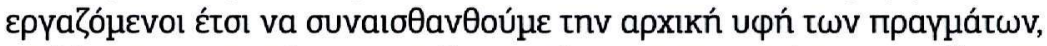

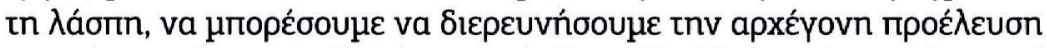

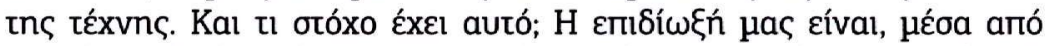

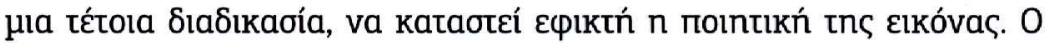

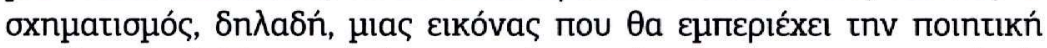

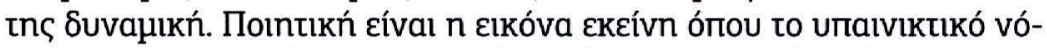

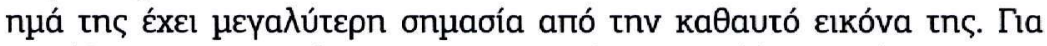

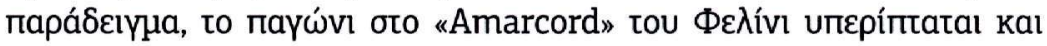

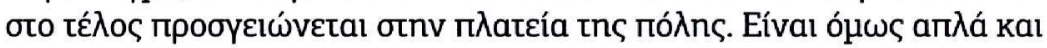

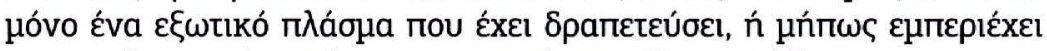

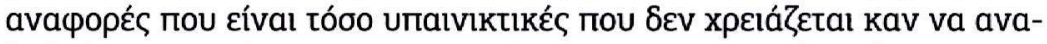

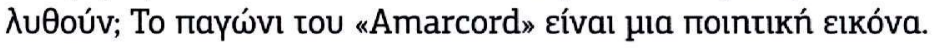

Ta חत

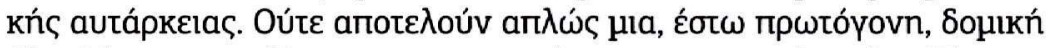

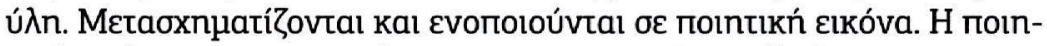

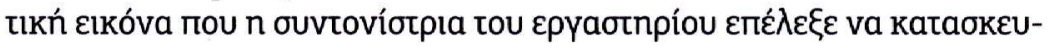

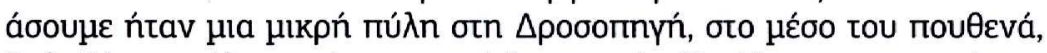

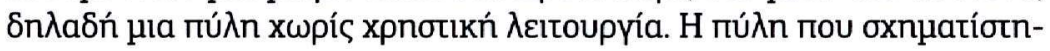

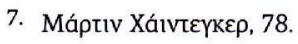




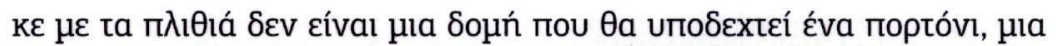

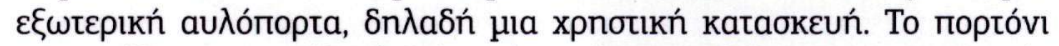

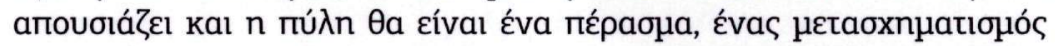

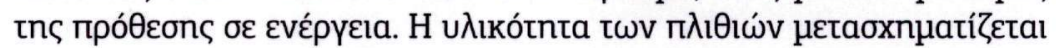

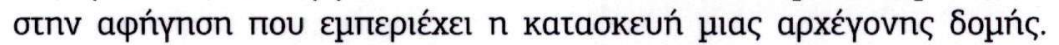

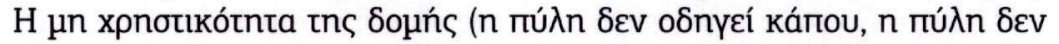

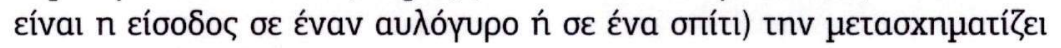

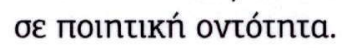

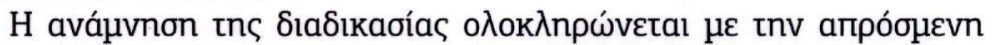

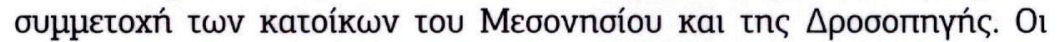

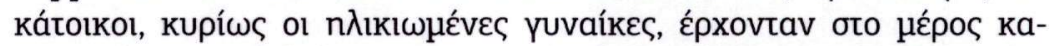

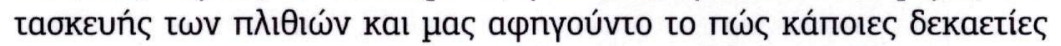

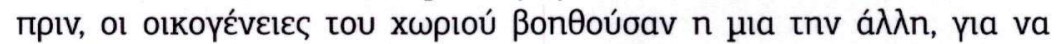

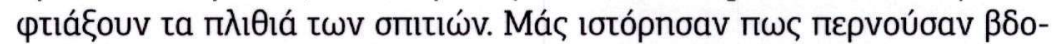

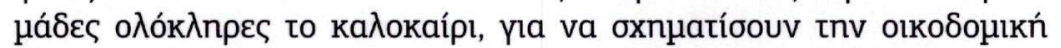

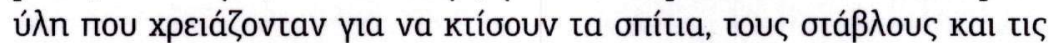

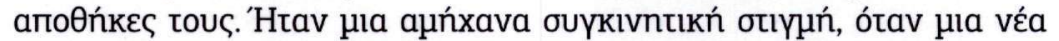

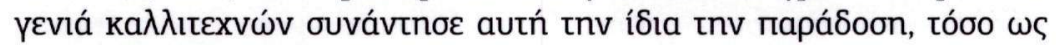

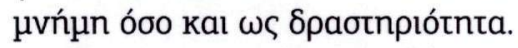

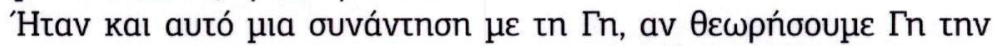

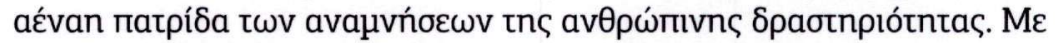

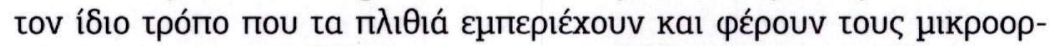

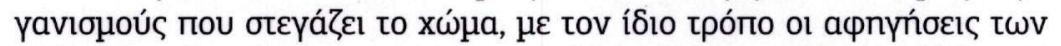

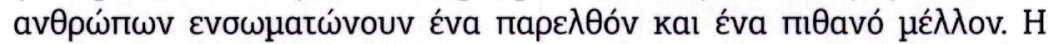

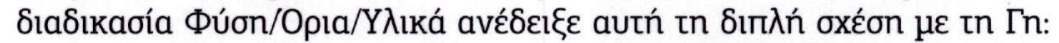

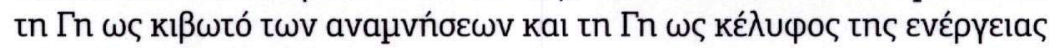

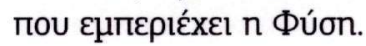

\section{ВIBАIOГРАФIA}

John Beardsley, Eartworks and Beyond, Abbeville Press, Néa Yópkn, 1998.

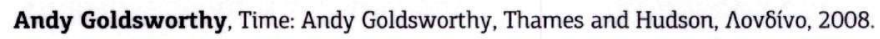

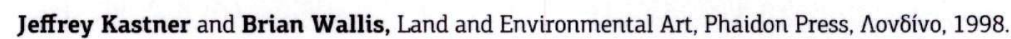

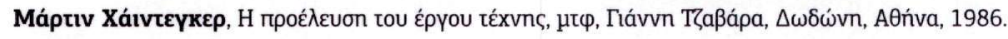

http://www.robertsmithson.com/films/txt/rundown.html

http://visualmarch.eetf.uowm.gr 